\title{
Volatile inhibitors of atmospheric corrosion of ferrous and nonferrous metals. IV. Application of the VNKh-L-408 inhibitor in an electrostatic field
}

\author{
A. I. Altsybeeva, V. V. Burlov, N. S. Fedorova and T. M. Kuzinova \\ All-Russia Research Institute of Petrochemical Processes, Zheleznodorozhnyi pr. 40, \\ St.Petersburg, 192148 Russian Federation.E-mail: altsybeeva@yandex.ru
}

\begin{abstract}
Some aspects of the application of VNKh-L-408 inhibitor in an electrostatic field (the kinetics of its evaporation from the surfaces of various metals, the causes of its higher efficiency upon electrostatic application, and the mechanism of its action) are discussed. A technology for electrostatic application of powdered inhibitor to metal surfaces has been developed.
\end{abstract}

Key words: electrostatic field, kinetics of evaporation, application technology.

Received May 24, 2013.

doi: $\underline{10.17675 / 2305-6894-2013-2-3-194-202}$

The method of electrostatic deposition of inhibitors to a metal surface or electrostatic spraying of inhibitors in an enclosure around a metal article to be protected is new $[1,2]$ and unparalleled, so we will discuss it here in more detail. Although this method has been introduced into commercial use, its mechanism is not understood in full; some physicochemical aspects of the process also remain unclear.

It is known that if it is possible to seal the space to be protected at least partially is a direct indication that a volatile inhibitor of atmospheric corrosion (VIAC) should be used. Depending on the operating or storage conditions for a metal article, the VIAC vapors propagate within the space by diffusion or by transfer with a gas flow. However, the use of many inhibitors is limited by their low volatility. The electrostatic method allows one to circumvent this problem and use VIACs with low vapor pressures when a metal article is only partially sealed or even not sealed at all.

Application of an inhibitor at a concentration of $\sim 10 \mathrm{~g} / \mathrm{m}^{2}$ to a metal surface in an electrostatic field (which corresponds to $\sim 60 \mathrm{~g} / \mathrm{m}^{3}$ of the air volume) ensures higher protection in comparison to its granulated forms (granlin, lingal, and tablin) at the same concentration, or to its application as powder in sachets suspended inside a metal article (the most laborious method) (see Table 2 in [3]). The high efficiency of this method was confirmed by field test data (Table 1).

The method essentially involves electrostatic deposition of a VIAC onto a metal surface until a charge density that is optimum for the inhibitor is reached, followed by treatment of the surface with an ionized gas flow produced by corona discharge. This results in a uniform distribution of the inhibitor over the surface (or throughout the space) 
to be protected as well as in its reduced evaporation rate and enhanced protective properties $[1,2]$.

Table 1. Field test data for the VNKh-L-408 corrosion inhibitor electrostatically applied to metals under atmospheric conditions of the Kirishi refinery (under a shed) for 12 months.

\begin{tabular}{|c|c|c|c|c|c|c|c|c|}
\hline \multirow{3}{*}{$\begin{array}{l}\text { Amount of the } \\
\text { inhibitor, } g / \mathrm{m}^{2} \text { of } \\
\text { the surface }\end{array}$} & \multicolumn{8}{|c|}{$\begin{array}{c}\text { Corroded area of the metals (\%) after } 6 \text { and } 12 \text { months } \\
\text { according to GOST (State Standard) } 9.311\end{array}$} \\
\hline & \multicolumn{2}{|c|}{ St3 Steel } & \multicolumn{2}{|c|}{ M1 Copper } & \multicolumn{2}{|c|}{ Ts1 Zinc } & \multicolumn{2}{|c|}{ D16 Aluminum } \\
\hline & 6 & 12 & 6 & 12 & 6 & 12 & 6 & 12 \\
\hline 10 & 0 & 0.02 & 0 & 0 & 0 & 0.01 & 0 & 0.01 \\
\hline 20 & 0 & 0 & 0 & 0.01 & 0 & 0.01 & 0 & 0.01 \\
\hline 0 & 25 & 100 & 0.12 & 15 & 0.18 & 100 & 0.01 & 0.15 \\
\hline
\end{tabular}

Note: After 42 months (3.5 years) of the field tests, the protective values of the VNKh-L-408 inhibitor are $\sim 95 \%$ for St3 steel and M1 copper, nearly $100 \%$ for D16 aluminum, and $20 \%$ for Ts 1 zinc.

The inhibitor in the form of an aerosol (a mixture of single molecules and agglomerates) is sprayed through a corona-forming (negative) electrode and transferred by a flow of dry air ( $P$ up to $1.5 \mathrm{~kg} / \mathrm{cm}^{2}$ ) to a grounded metal; the electrostatic field is created between the grounded part and the discharge electrode at the end of the spray gun using a high-frequency voltage converter.

It is known that VIACs can be spontaneously adsorbed from a gas phase on metals:

- prior to the formation of a corrosive film of an electrolyte on a metal surface;

- after film condensation on a surface;

- from an electrolyte film saturated with the inhibitor.

The effects of VIACs on the corrosion characteristics of metals differ in the three cases listed above. The strongest effect is attained when the inhibitor is preadsorbed from the gas phase; the weakest effect is observed when the inhibitor adsorption is preceded by moisture condensation onto the metal surface. Therefore, a VIAC should be used when it can be adsorbed on a metal surface prior to the condensation of a corrosive electrolyte film [2].

Saturation of a metal surface with a VIAC is not instantaneous. To provide reliable metal passivation, a critical period of time is required for sufficient adsorption of an inhibitor and strong chemical bonding between the inhibitor and the metal surface. Electrostatic application of inhibitors onto metals minimizes the critical time because of rapid adsorption of the inhibitor and ensures that the inhibitor reaches the stagnant zones of the equipment [2]. This explains why the electrostatic method provides a more efficient protection of metals. 
It is generally accepted that the electron density on the adsorption center of the inhibitor molecule is one of the factors that determine its protective properties. In the formation of a metal-inhibitor adsorption bond, both chemisorption and electrostatic interactions take a considerable part; so the strength of a chemisorption bond and the protective effect of the inhibitor depend on both the apparent charge on the adsorption site and the electrical asymmetry of the inhibitor.

That is why it is more correct to relate the efficiency of an inhibitor both to the electron density on the adsorption site of its molecule and to the dipole moment that characterizes its electrical asymmetry.

It has been demonstrated [2] that the increased efficiency of the NDA inhibitor applied in an electrostatic field is due to its high dipole moment (4.14 D). It is assumed that a non-zero dipole moment of a compound is an essential criterion for it to be selected for electrostatic application onto a metal.

Let us analyze how the evaporation rates of the NDA, VNKh-L-20, and VNKh-L-408 inhibitors applied in an electrostatic field to steel vary with their dipole moments (Table 2). The dipole moment of NDA is taken from [4]. Quantum chemical calculations of the molecular diagrams of the VNKh-L-20 and VNKh-L-408 inhibitors were performed using the HyperChem Version Professional Release 6.03 program (Hypercube Inc. (C) 2001) in CNDO/2 approximation without geometry optimization (standard bond lengths and bond angles, the Build model in the Single Point mode). The Polak-Ribiere geometry optimization was used in dipole moment calculations.

Table 2. Evaporation rates of inhibitors electrostatically applied to St3 steel.

\begin{tabular}{cccc}
\hline Inhibitor & Dipole moment, $\mathbf{D}$ & $\begin{array}{c}\text { Evaporation in } \\
\text { open air, } \\
\mathbf{g} /\left(\mathbf{m}^{2} \mathbf{d a y}\right)\end{array}$ & $\begin{array}{c}\text { Evaporation within an } \\
\text { enclosure, } \\
\mathbf{g} /\left(\mathbf{m}^{2} \mathbf{d a y}\right)\end{array}$ \\
\hline NDA & 4.140 & $0.060^{*}$ & $0.030^{*}$ \\
\hline VNKh-L-408 & 2.952 & 0.078 & 0.058 \\
\hline VNKh-L-20 & 1.782 & 0.108 & 0.082 \\
\hline
\end{tabular}

Note: *Data from [2].

The data obtained reveal a distinct correlation between the evaporation rate and dipole moment of the inhibitor electrostatically applied onto the metal: the higher the dipole moment, the higher the capability of the species for electrostatic interaction with metals but the lower the evaporation rate.

The size and complex configuration of the VNKh-L-408 molecule might cause some difficulty in its orientation during the adsorption on a metal. However, under the assumption that the dipole moment increases in an applied electrostatic field and that the conditions for interaction of adsorption centers with the metal surface become more favorable, an increased adsorptivity of its molecule on the metal should be expected. We 
will demonstrate below that additional exposure to an electrostatic field (i.e., treatment of the inhibited metal surface with an extra corona discharge for $5 \mathrm{~min}$ ) makes the inhibitor less volatile, which can be attributed to the strengthening of the adsorption bonds between VNKh-L-408 and the metal.

We studied the kinetics of evaporation of the VNKh-L-408 inhibitor electrostatically applied to various metals.

The test conditions were as follows (types 1, 2, and 3):

1. Evaporation of the VNKh-L-408 inhibitor from the steel surface in open air at $20 \pm 2{ }^{\circ} \mathrm{C}$.

2. Evaporation of the VNKh-L-408 inhibitor from the surfaces of M1 copper and St3 steel in open air at a temperature difference from 20 to $-20^{\circ} \mathrm{C}$.

3. Evaporation of the VNKh-L-408 inhibitor from the surfaces of various metals in a hermetically sealed space.

Mathematical processing of the experimental data array was performed using the MATLAB vector matrix laboratory.

\section{Calculation program:}

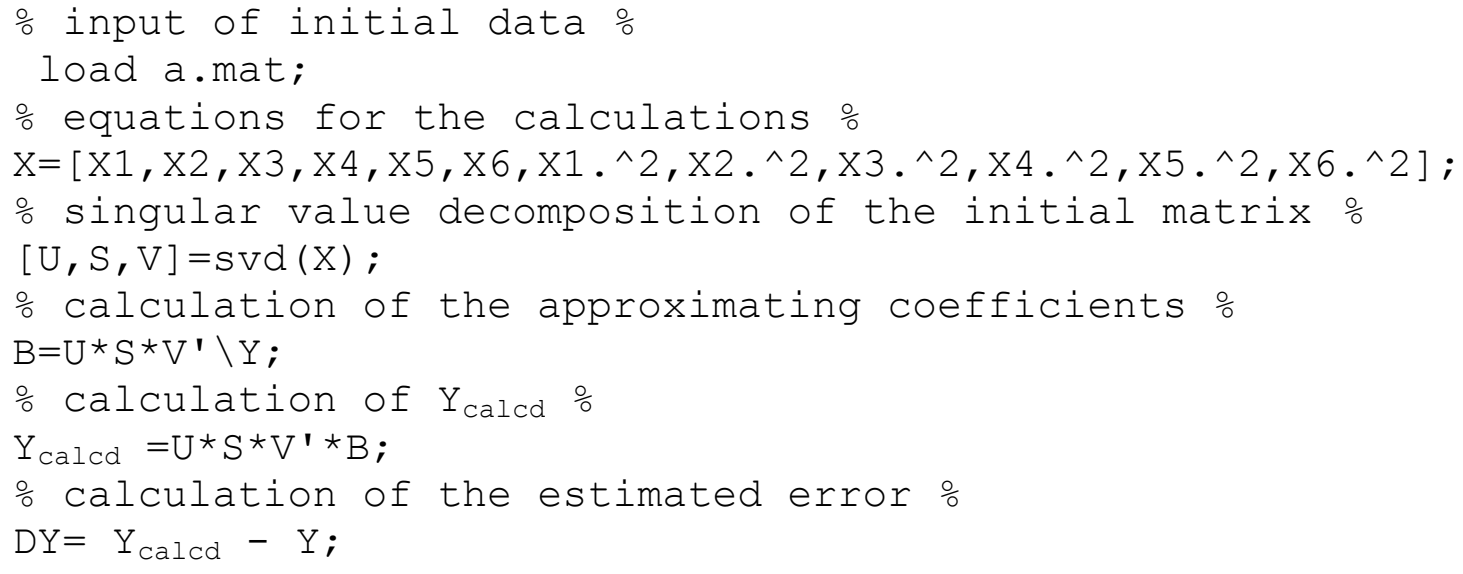

The kinetic data obtained revealed that:

- the monotonic decrease in the concentration of the VNKh-L-408 inhibitor with time allows its interpolation over extended periods of time using both numerical methods and appropriate analytical interpolating equations;

- the logarithmic curve fits best to the experimental evaporation rates of the VNKh-L408 inhibitor from steel in open air (type 1). For this reason, we proposed the following formula for analytical interpolation:

$$
K=\frac{A}{1+B \cdot e^{-C t}},
$$


where the coefficients $A, B$, and $C$ were calculated by an iterative procedure aimed at minimizing the difference between the calculated and experimental data.

Figures $1 a$ and $1 b$ display the interpolations of the initial plots $K=f(Y)$ to 500 and 700 days, respectively. These results were obtained using shape-retaining piecewise linear interpolation with Hermite splines (cubic polynomials).

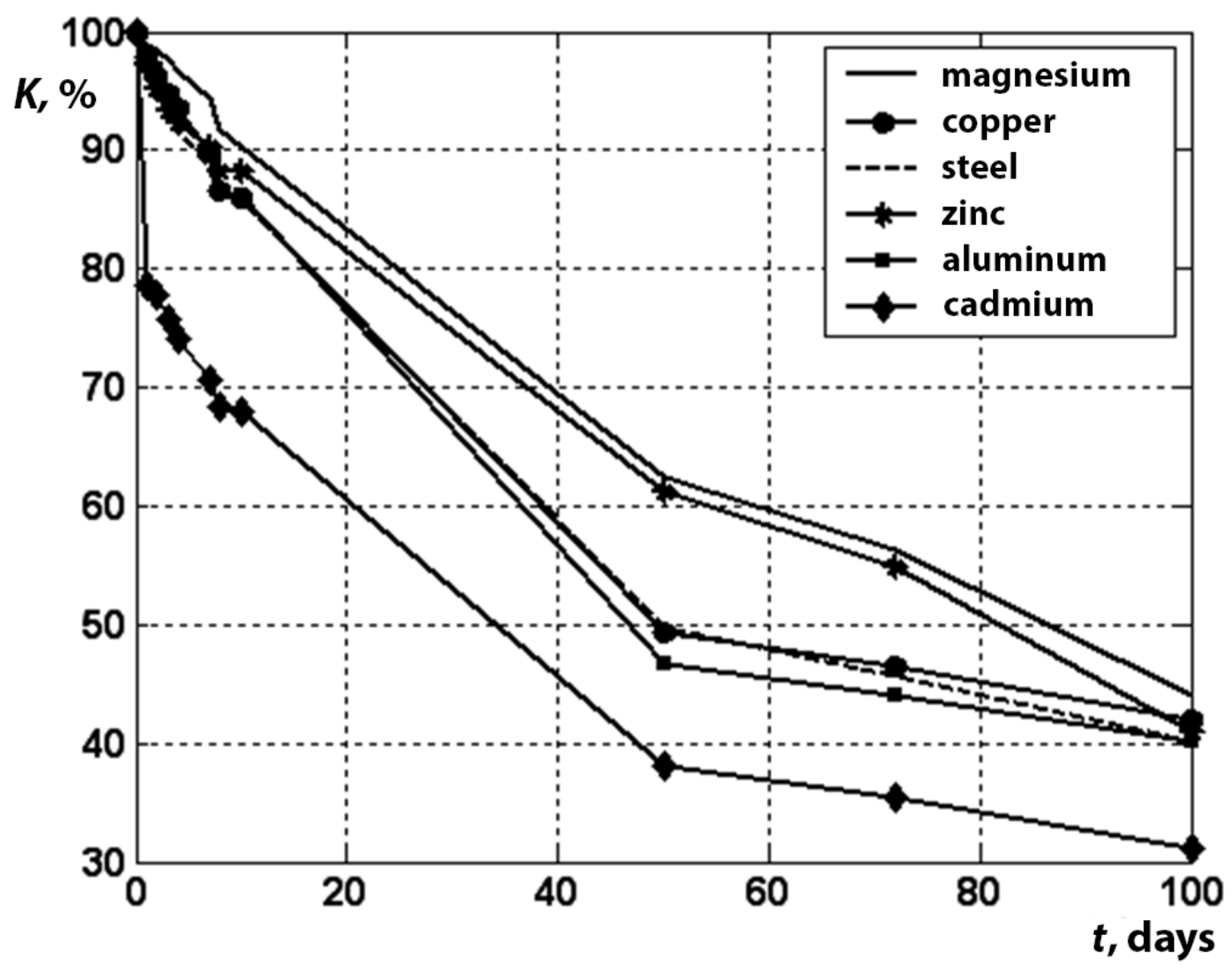

Fig. 1. Interpolation of the initial curves $K=f(Y)$ for type 1 experiment (for six specimens).

We have found that:

- extra treatment of inhibited steel specimens with corona discharge lowers the evaporation rate of the inhibitor from the metal surface so that residual amounts of the inhibitor are retained on the steel surface for prolonged periods of time. Without this extra treatment, the concentration of the inhibitor tends to zero over the same periods of time;

- the experimental conditions (type 1) simulate the storage of metal articles in an unsealed warmed room. However, extra corona discharge treatment of an inhibited metal surface will make its corrosion protection efficient under more drastic storage conditions, as confirmed by field test results; 
- the main trends in the evaporation of an electrostatically applied inhibitor from steel and copper surfaces (type 2) are the same during the first 200 days. When the inhibitor concentration reaches $\sim 4 \mathrm{~g} / \mathrm{m}^{2}$, the steel specimens gain weight, probably because of corrosion resulting in the formation of some amounts of corrosion products. It should be noted that metal specimens also gain weight during corrosion tests in an environmental cabinet (temperature difference $40-20^{\circ} \mathrm{C}$, relative humidity $98-100 \%$ ): the weight gain is observed after 60 days for steel specimens and after 90 days for copper ones, with virtually no visible corrosion damage to both.
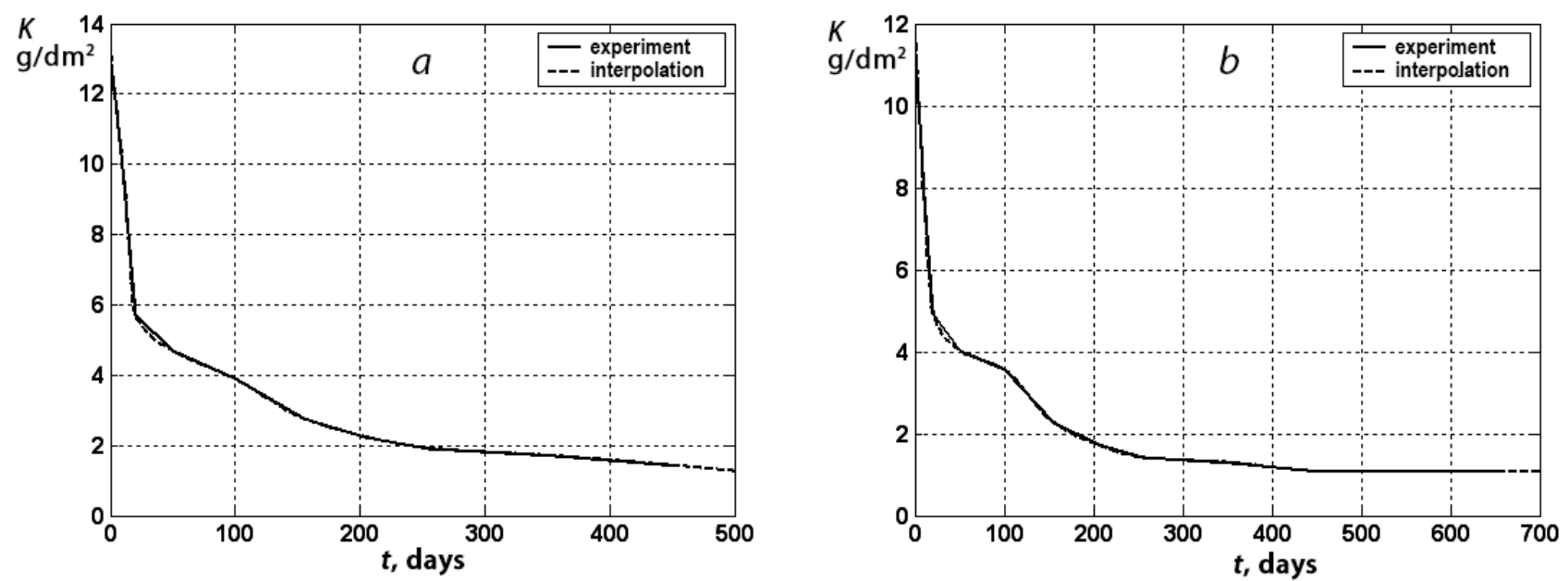

Fig. 2. Changes in the concentration gradient of the electrostatically applied inhibitor VNKh$\mathrm{L}-408(K, \%)$ with time during its evaporation from various metals in a hermetically sealed enclosure (type 3 ).

The kinetic data obtained in type 3 are shown in Fig. 2. It follows from these data that:

- the variation in the concentration of the electrostatically applied inhibitor obeys the logarithmic law for all the metals studied and can also be described by the formula proposed above;

- after a 50-day exposure, once $\sim 40-60 \%$ of the inhibitor has evaporated, its evaporation rate decreases;

- according to the test results obtained in type 3, the metals can be conventionally classified into two groups based on the features of evaporation of the inhibitor from the metal surfaces:

- group 1 (copper, steel, and aluminum) is characterized by a relatively high negative concentration gradient of the inhibitor in the first 50 days. The concentration gradient then decreases and the inhibitor will be retained on the metal surface for a predicted period of more than 250 days; 
- group 2 (magnesium and zinc) is characterized by a lower negative concentration gradient of the inhibitor in the first 70 days. The concentration gradient then increases substantially and the inhibitor will be retained on the metal surface for a predicted period of $\sim 150$ days;

- the inhibitor concentration on cadmium decreases abruptly in the first 24 hours of the test, while this decrease slows down substantially later on. The predicted period during which the inhibitor will be retained on cadmium is more than 200 days.

The metals within either group have the same crystal lattices: cubic in copper, iron (steel), and aluminum and closest packed hexagonal in magnesium, zinc, and cadmium. Apparently, this accounts for similar patterns of the inhibitor evaporation, which tends to bind to the metals through its heteroatomic groups and ring $\pi$-electrons forming donoracceptor bonds.

However, all commercial metals are not single crystals; they consist of many crystallites with irregular exterior shapes. A real metal surface is a combination of differently oriented crystallites, grain boundaries, and foreign inclusions. It is this combination that makes any metal surface fundamentally inhomogeneous and complicates an unambiguous interpretation of the relationships obtained.

Ignoring the conventional classification of the metals into the above groups, one can see that they form the following series according to the evaporation rate of the VNKh-L408 inhibitor:

$$
\mathrm{Mg}<\mathrm{Zn}<\mathrm{Fe} \approx \mathrm{Cu}<\mathrm{Al}<\mathrm{Cd} .
$$

This series differs from that of the atmospheric corrosion inhibition factors [5] as well as from the series of the metals arranged by melting points, stability of hydroxo complexes, first ionization potentials, Nechaev's "resonance" potentials, and electron work functions, which were discussed in $[5,6]$ in the context of possible prediction of the inhibitive properties of organic compounds.

This confirms our previous conclusion that the general concept of evaluating the adsorbability of chemical compounds on metals and, hence, their inhibitive properties based on the general electronic characteristics of compounds and metals (ionization potentials, "resonance" potentials, and electron work functions) fails in accurate prediction of the inhibitive effects of chemical compounds on various metals [5].

In [5], we have demonstrated that the high protective effect of the inhibitor on steel, copper, and aluminum is accounted for by the fact that the ionization potentials of the $\mathrm{N}$ atoms and the ring $\pi$-electrons are close to the "resonance" potentials of the metals and their oxides. For zinc, the ionization potentials of those atoms are close only to the "resonance" potential of oxidized zinc; for cadmium (in the form of oxide), adsorption bonds between the metal surface and the inhibitor are formed by the $\mathrm{O}$ atoms, while the $\mathrm{N}$ heteroatoms cannot be involved in these bonds. It should be taken into account that both the zinc and cadmium surfaces in a humid atmosphere mainly bear the corresponding 
hydroxides, which undoubtedly changes the pattern of adsorption of chemical compounds on their surfaces and results in poor protection of these metals from corrosion.

The high protection efficiency of VNKh-L-408 electrostatically applied to a metal surface can also be explained by the formation of protective layers of chemically and physically adsorbed molecules. One can assume that a physically adsorbed layer obtained by contact electrostatic deposition is thicker than a chemisorbed layer. The thickness of the physically adsorbed layer is large enough to prevent atmospheric moisture from reaching the metal surface and initiating VIAC hydrolysis.

The adsorption bond strength depends on the metal and its electronic structure as well as on the complexing ability of the inhibitor molecule. When considering the structure of the VNKh-L-408 inhibitor, note that the presence of a benzotriazole ring is favorable for complexation with metals (e.g., copper and zinc).

The VNKh-L-408 inhibitor contains several fragments responsible for the protection of various metals from corrosion, as demonstrated above. The inhibition effect of VNKhL-408 on the corrosion of various metals through the formation of donor-acceptor bonds seems to be enhanced when this inhibitor is applied in an electrostatic field, as confirmed by corrosion tests.

Electrostatic application of powdered VNKh-L-408 inhibitor to a metal surface includes the following steps:

- putting of a metal article in a spraying setup on a grounded device;

- getting the spraying setup energized according to the operating instruction;

- deposition of powdered inhibitor onto a metal surface in an electrostatic field generated between the discharge electrodes at the end of the spray gun and the grounded metal article;

- treatment of the protected surface of the metal article with a flow of ions produced by corona discharge.

The main modes of application of the powdered inhibitor that vary with the metal surface to be protected and the main types of equipment for electrostatic application of the inhibitor are specified in GOST (State Standard) 9.014, Appendix 7 [7].

\section{Conclusions}

1. Application of inhibitors onto metals in an electrostatic field minimizes the critical time required for reliable passivation of the metal because of rapid adsorption of the inhibitor. In addition, the inhibitor is supplied to the stagnant zones of the equipment, which accounts for a better protection of metal articles from corrosion by the electrostatic method.

2. We found a correlation between the evaporation rate and dipole moment of an inhibitor electrostatically applied to a metal surface: the higher the dipole moment, the higher the capability of the species for electrostatic interactions with metals and the lower the evaporation rate. 
3. We have studied the evaporation kinetics of the VNKh-L-408 inhibitor electrostatically applied onto various metals, revealed a monotonic decrease in the concentration of the inhibitor with time, and interpolated its changes to rather extended periods of time using both numerical methods and appropriate analytical interpolating equations.

4. The high protective capability of VNKh-L-408 electrostatically applied to a metal surface is explained by the formation of protective layers of chemisorbed and physically adsorbed molecules.

5. We have developed a technology for electrostatic deposition of powdered inhibitor onto metal surfaces.

\section{References}

1. RF Patent 2078851, 1997; Byull. Izobret., 1997, 13, 2 (in Russian).

2. V. V. Burlov, A. I. Altsybeeva and I. V. Parputs, Zashchita ot korrozii oborudovaniya NPZ (Protection of Refinery Equipment from Corrosion), St. Petersburg, Khimizdat, 2005, Section 3.2, p. 181 (in Russian).

3. A. I. Altsybeeva, V. V. Burlov, N. S. Fedorova and T. M. Kuzinova, Int. J. Corros. Scale Inhib., 2013, 2, no. 1, 9. doi: 10.17675/2305-6894-2013-2-1-009-016

4. E. F. Shott-L'vova and Ya. K. Syrkin, Izv. Akad. Nauk SSSR, Otd. Khim. Nauk, 1960, 139 (in Russian).

5. A. I. Altsybeeva, V. V. Burlov, N. S. Fedorova, T. M. Kuzinova and G. F. Palatik, Int. J. Corros. Scale Inhib., 2012, 1, no. 1, 51. doi: 10.17675/2305-6894-2012-1-1-051-064

6. A. I. Altsybeeva, V. V. Burlov, N. S. Fedorova, T. M. Kuzinova and G. F. Palatik, Int. J. Corros. Scale Inhib., 2013, 2, no. 1, 9. doi: 10.17675/2305-6894-2013-2-1-009-016

7. Unified System of Protection from Corrosion and Ageing. Temporary Protection of Articles. General Requirements. - Introduction 1980-01-01, GOST (USSR Standard) 9.014-78, Moscow, Russian State Standard: Standartinform, 2005 (in Russian). 